\title{
ВЫХОД ПОСАДОЧНОГО МАТЕРИАЛА ЗЕМЛЯНИКИ В ЗАВИСИМОСТИ ОТ СХЕМЫ ПОСАДКИ И СОРТОВЫХ ОСОБЕННОСТЕЙ МАТОЧНЫХ РАСТЕНИЙ
}

\author{
A.F. Stepanov, N.A. Bondarenko, V.V. Knaub

\section{THE YIELD OF PLANTING MATERIAL DEPENDING ON PLANTING SCHEME AND HIGH-QUALITY FEATURES OF UTERINE PLANTS}

Степанов Александр Федорович - д-р с.-Х. наук, проф. кафр. садоводства, лесного хозяйства и защиты растений Омского государственного аграрного университета им. П.А. Столыпина, г. Омск.

E-mail: af.stepanov@omgau.org

Бондаренко Надежда Александровна - канд. c.-х. наук, доц. каф. садоводства, лесного хозяйства и защиты растений Омского государственного аграрного университета им. П.А. Столыпина, г. Омск. E-mail: na.bondarenko@omgau.org

Кнауб Валерия Вячеславовна - магистрант каф. садоводства, лесного хозяйства и защиты растений Омского государственного аграрного университета им. П.А. Столыпина, г. Омск. E-mail:vv.knaub1833@omgau.org

Цель работы - выявление влияния двух схем посадки маточных растений на усообразовательную способность и выход стандартного посадочного материала сортов земляники. Исследования проводили в 2016-2019 ге. в южной лесостепи Омской области на луговочерноземной почве. Установлено, что разреженная (блочная) посадка земляники в маточнике способствует лучшему формированию листового аппарата у высаженной рассады. $K$ кониу августа число листьев на растении при загущенной схеме посадки 0,9×0,2 м составляem om 8,7 до 14,0 шт., а при разреженной 0,9х0,9 м увеличивается до 12,0-25,7 штук. Появление первых усов земляники наблюдается 10-30 июня, массовое образование - в середине июля - второй декаде августа. Cорта земляники при блочной посадке рассады отличаются повышенной усообразующей способностью, к кониу августа имеют 12,7-19,0 усов на растении, тогда как при загущенной лишь 9,713,0 шт. Наиболее длинные усы (138-159 см) имеют сорта Анастасия и Первоклассница,
Stepanov Alexander Fedorovich - Dr. Agr. Sci., Prof., Chair of Gardening, Forestry and Plants Protection, Omsk State Agrarian University named after P. A. Stolypin, Omsk.

E-mail: af.stepanov@omgau.org

Bondarenko Nadezhda Alexandrovna - Cand. Agr. Sci., Assoc. Prof., Chair of Gardening, Forestry and Plants Protection, Omsk State Agrarian University named after P. A. Stolypin, Omsk.

E-mail: na.bondarenko@omgau.org

Knaub Valeria Vyacheslavovna - Magistrate Student, Chair of Gardening, Forestry and Plants Protection, Omsk State Agrarian University named after P. A. Stolypin, Omsk.

E-mail:vv.knaub1833@omgau.org

меньше - Даренка и Слоненок - 110,7-120,7 см. При разреженной схеме посадки к осени от одного куста земляники образуется стандартных розеток больше, но выход рассады с 1 га из-за разного числа высаженных маточных растений на этой площади выше в 3,84,4 раза при загущенной и составляет 1727,8 2238,9 штук. При выкопке земляники весной выход стандартной рассады в среднем по всем сортам при загущенной посадке на $28,8 \%$, а блочной - на 21, 3 \% больще, чем при выкопке осенью. При обеих схемах посадки и выкопке осенью выход стандартной рассады сортов земляники составляет 43,2-77,4 \%, а весной - увеличивается до 72,4-85,7 \%. Наuбольший выход стандартной рассады с 1 га обеспечивает сорт Первоклассница.

Ключевые слова: земляника, маточник, схема посадки, сорт, продуктивность.

The aim of the study was to identify the influence of two schemes for planting mother plants on tendril-making capacity and the yield of standard 
planting material of strawberry varieties. The studies were conducted in 2016-2019 in the southern forest-steppe of Omsk Region on meadow chernozem soil. It was established that sparse (block) planting of wild strawberries in mother liquor had contributed to a better formation of the leaf apparatus in planted seedlings. By the end of August, the number of leaves on a plant with a thickened planting pattern of $0.9 \times 0.2 \mathrm{~m}$ was from 8.7 to 14.0 pcs. And with rarefied $0.9 \times 0.9 \mathrm{~m}$, it increased to 12.0-25.7 pcs. The appearance of the first strawberry tendrils was observed on June, 10-30, mass formation - in mid-July - the second decade of August. The varieties of strawberries at block planting of seedlings were distinguished by increased tendril-forming ability; by the end of August they had 12.7-19.0 tendrils on the plant, while with thickened only 9.7-13.0 pcs. The longest tendrils (138$159 \mathrm{~cm})$ were observed in Anastasia and Pervoklassnitsa varieties, less - in Darenka and Slonenok - 110.7-120.7 cm. With a sparse planting pattern, more rosettes formed standard rosettes from one bush of autumn, but the seedlings yield per 1 hectare due to different number of planted mother plants in this area, were 3.8-4.4 times higher with thickened and amounted to 1727.82238.9 pcs. When digging strawberries in spring, the yield of standard seedlings on average for all the varieties with a thickened planting was $28.8 \%$, and block seedlings - $21.3 \%$ more than when digging in the fall. For both planting and digging schemes in the fall, the yield of standard seedlings of strawberry varieties was $43.2-77.4 \%$, and in spring it increased to 72.4-85.7\%. The highest yield of standard seedlings from 1 hectare was provided by Pervoklassnitsa variety.

Keywords: wild strawberry, mother liquor, planting pattern, variety, productivity.

Введение. Для многих стран мира особую ценность представляют ягодные культуры, в частности земляника. Благодаря скороплодности, раннему формированию урожая, высоким вкусовым и технологическим качествам ягод, земляника является одной из популярных ягодных культур. Ее выращивают более чем в 75 странах, где ежегодно получают 3,6 млн т ягод [1]. В России ежегодно собирают 165 тыс. т ягод земляники, или около $6 \%$ мирового ее производства, из которых 95 \% этого объема выращивается населением [2].
В Омской области доля садов в хозяйствах населения составляет 6,14 тыс. га, или 97,6\% от общей их площади. Под семечковыми культурами занято около 31 \%, под косточковыми 28,4 , под ягодными - 38,9 \%. Среди ягодных культур площадь под земляникой уступает лишь малине и черной смородине [3]. Земляника была и остается одной из наиболее популярных ягодных культур, спрос на свежие ее ягоды и продукты их переработки непрерывно растет [4]. Однако посадочного материала новых сортов этой культуры для полного удовлетворения потребностей населения недостаточно.

Выращивают рассаду земляники в специальных маточниках. Схемы посадки земляники в них ученые предлагают разные. Одни из них [5-7] обязательным условием выращивания рассады земляники в маточнике считают разреженное размещение растений по системе блоков $90 \times 90 \mathrm{~cm}$ (12 тыс. шт/га), 120×120 см (7 тыс. шт/га) или лент 100x45 см (22 тыс. шт/га), 140x70 см (10 тыс. шт/га) с промежутками в ленте 1,0-1,5 м. Допускают также и рядовой способ размещения растений с междурядьями $80 \mathrm{~cm}$, а в ряду - 2040 cм. Другие ученые [8, 9] рекомендуют ленточный $100+40 \times 90$ см и рядовой - 140×20 см способ посадки в маточнике растений земляники. На Новосибирской плодово-ягодной станции также практикуют рядовую посадку земляники в маточнике, но с междурядьями 90 и 70 см, в ряду - через 20-25 см [8].

Рассаду земляники для летней посадки заготавливают в августе, для весенней - в конце сентября - начале октября или в мае. В последние годы хозяйства России, производящие землянику, в качестве посадочного материала все шире используют рассаду «фриго». Осенью растения выкапывают, с них удаляют землю и листья, обрабатывают фунгицидами, сортируют, связывают в пучки и отправляют на хранение. Хранят рассаду земляники «фриго» в полиэтиленовых пакетах в холодильных камерах при температуре от 0 до $-2{ }^{\circ} \mathrm{C}$ и влажности не более $90 \%$ [7].

Цель исследования. Выявить влияние схемы посадки маточных растений на усообразовательную способность и выход стандартного посадочного материала сортов земляники в условиях южной лесостепи Омской области.

Задачи: определить у маточных растений земляники динамику нарастания листового аппарата; усообразовательную способность и темпы роста усов; выход стандартной рассады. 
Объект и методы исследования. Исследования проводили в 2016-2019 гг. в южной лесостепи Омской области в Учебно-опытном хозяйстве на территории УНПЛ «Садоводство» Омского ГАУ им. П.А. Столыпина. Почва опытного участка - лугово-черноземная с содержанием гумуса $5,72 \%$, мощность гумусового горизонта 40-60 см, отличается высоким содержанием в пахотном слое общего азота и валового фоссрора. Структура пылевато-комковатая. Реакция почвенного раствора слабокислая.

Объект исследования - сорта земляники Первоклассница (контроль), Даренка, Анастасия, Слоненок. Предшественник - пар черный. Схема посадки маточных растений - загущенная $(0,9 \times 0,2 \mathrm{м})$ и блочная $(0,9 \times 0,9 \mathrm{M})$. Маточник закладывали рассадой земляники с закрытой корневой системой в 2016 г. - 6 мая, в 2017 г. 23, в 2018 г. - 29 мая. Срок эксплуатации маточника один год. Наблюдения за темпами образования листьев у маточных кустов земляники проводили через каждые 10 суток. Образующиеся усы при схеме посадки 0,9×0,9 м заправляли внутрь блока, при схеме 0,9х0,2 м - в междурядье смежных рядов, цветоносы по мере их появления удаляли. Выход рассады земляники определяли путем выкопки маточных растений вместе с образовавшимися розетками осенью в третьей декаде сентября и весной - в середине мая. Подсчитывали укоренившиеся и неукоренившиеся розетки. Полученную рассаду сортировали на стандартную и нестандартную.

Учетная площадь делянки $10 \mathrm{~m}^{2}$, повторность - 3-кратная, размещение вариантов систематическое. Наблюдения и учеты проводили по методике сортоизучения плодовых, ягодных и орехоплодных культур [10] и в соответствии с ГОСТ P 53135-2008 [11].

Результаты исследования и их обсуждение. Наблюдения показали, что в первоначальный период после посадки рассады в мае до 10 июня нарастание листьев у сортов земляники шло слабо, но в последующем после хорошего укоренения растений рост их активизировался. На каждом маточном кусте к 20 июня при обеих схемах посадки их насчитывалось от 6,7 до 11 штук или возрастало на 2,7-7,0 листьев в сравнении с числом их при посадке в мае (табл. 1). Активное нарастание листьев у всех сортов земляники шло в июле и продолжалось до второй декады августа. К концу августа у большинства сортов земляники, за исключением Даренки, образование новых листьев прекращалось и наблюдалось отмирание из них старых. Средняя продолжительность жизни листьев земляники составляла 56-69 суток.

\section{Влияние схемы посадки на темпы нарастания листьев у маточного куста земляники (2016-2018 гг.), шт.}

\begin{tabular}{|l|c|c|c|c|c|c|}
\hline & Число листьев & \multicolumn{5}{|c|}{ Дата учета } \\
\cline { 3 - 7 } \multicolumn{1}{|c|}{ Сорт } & при посадке & $20.05-01.06$ & 20.06 & 20.07 & 20.08 & 31.08 \\
\hline \multicolumn{7}{|c|}{ Схема посадки 0,9х0,2 м } \\
\hline $\begin{array}{l}\text { Первоклассница } \\
\text { (контроль) }\end{array}$ & 3 & 4,0 & 8,3 & 8,3 & 10,7 & 8,7 \\
\hline Анастасия & 4 & 4,3 & 11,0 & 10,0 & 10,7 & 9,3 \\
\hline Даренка & 4 & 3,7 & 6,7 & 11,0 & 13,7 & 14,0 \\
\hline Слоненок & 4 & 4,0 & 6,7 & 9,7 & 11,7 & 9,7 \\
\hline \multicolumn{7}{|c|}{ Схема посадки 0,9х0,9 м } \\
\hline $\begin{array}{l}\text { Первоклассница } \\
\text { (контроль) }\end{array}$ & 4 & 4,3 & 9,3 & 10,0 & 13,7 & 12,0 \\
\hline Анастасия & 4 & 4,0 & 8,0 & 11,7 & 15,7 & 15,7 \\
\hline Даренка & 4 & 3,7 & 7,7 & 13,0 & 23,0 & 25,7 \\
\hline Слоненок & 3 & 3,3 & 7,7 & 14,0 & 20,0 & 18,3 \\
\hline
\end{tabular}

Сорт земляники Даренка отличался формированием большего числа листьев в кусте в течение всей вегетации растений. Например, при блочной посадке $(0,9 \times 0,9$ м) 31 августа их насчитывалось на одном растении 25,7 шт., тогда

Таблица 1

как у других сортов 12,0-18,3 листьев. Листья у этого сорта имели средней длины черешки с большими, слегка сморщенными и густо опушенными листочками, которые изгибались и наклонялись вниз. Блочная посадка рассады к 
концу августа способствовала формированию большего (в 1,4-1,9 раза) числа листьев у сортов земляники в сравнении с загущенной.

Появление первых усов у земляники, в зависимости от сортовых особенностей и схемы посадки, наблюдалось в период цветения, 10-30 июня (табл. 2). Массовое образование усов у сортов земляники отмечалось в середине июля - второй декаде августа, после окончания плодоношения. К концу августа число усов на каж- дом растении насчитывалось от 9,7 шт. у сорта Анастасия при загущенной посадке до 19 шт. у сорта Слоненок при блочной. Все сорта земляники при блочной посадке рассады в маточнике отличались повышенной усообразующей способностью, к концу августа имели 12,7-19,0 усов на растении, тогда как при загущенной лишь 9,7-13,0 штук. Разреженная посадка создавала благоприятные условия для роста маточных кустов и их вегетативного потомства.

Таблица 2

\section{Динамика образования усов земляники в зависимости от схемы посадки маточных растений (2016-2018 гг.), шт.}

\begin{tabular}{|c|c|c|c|c|c|c|}
\hline \multirow{2}{*}{ Сорт } & \multicolumn{5}{|c|}{ Дата учета } & \multirow{2}{*}{$\begin{array}{c}\text { Побегообразовательная } \\
\text { способность, \% }\end{array}$} \\
\hline & 20.06 & 10.07 & 20.07 & 20.08 & 31.08 & \\
\hline \multicolumn{7}{|c|}{ Схема посадки 0,9×0,2 м } \\
\hline $\begin{array}{l}\text { Первоклассница } \\
\text { (контроль) }\end{array}$ & 3,0 & 7,0 & 8,3 & 11,3 & 13,0 & 100,0 \\
\hline Анастасия & 2,0 & 6,3 & 7,3 & 9,3 & 9,7 & 90,7 \\
\hline Даренка & 1,0 & 4,7 & 6,3 & 10,0 & 10,3 & 73,6 \\
\hline Слоненок & 1,0 & 5,0 & 6,0 & 10,7 & 10,3 & 91,5 \\
\hline \multicolumn{7}{|c|}{ Схема посадки 0,9х0,9 м } \\
\hline $\begin{array}{l}\text { Первоклассница } \\
\text { (контроль) }\end{array}$ & 2,3 & 6,3 & 7,3 & 12,3 & 13,3 & 97,1 \\
\hline Анастасия & 1,7 & 5,0 & 8,0 & 12,3 & 12,7 & 80,9 \\
\hline Даренка & 1,3 & 4,7 & 7,0 & 14,3 & 18,0 & 70,0 \\
\hline Слоненок & 1,3 & 5,0 & 8,3 & 15,3 & 19,0 & 95,0 \\
\hline
\end{tabular}

У земляники усы образуются из вегетативных почек, расположенных в пазухе листьев, поэтому имеется зависимость числа образующих усов от числа листьев на растении. Но усы могут образовываться не из каждой пазушной почки, что зависит от биологических особенностей сорта [7]. Наиболее высокой побегообразовательной способностью при обеих схемах посадки отличался сорт Первоклассница - 97,1-100 \%. У других сортов этот показатель варьировал от 70 до $90 \%$ (табл. 2). Схема посадки рассады земляники в маточнике значительного влияния на побегообразовательную способность сортов не оказывала.

Темпы роста усов у сортов земляники различны. В первоначальный период, в июне, активнее росли усы у сорта Первоклассница и слабо у сорта Слоненок, к 30 июня длина их составляла соответственно 38,3-43,0 и 19,3-24,0 см (табл. 3). Наиболее длинные усы (138-159 см) к окончанию августа имели сорта Анастасия и Первоклассница, тогда как у сортов Даренка и Слоненок они составляли лишь 110,7-120,7 см.

Таблица 3

Динамика роста усов у маточных кустов земляники, см

\begin{tabular}{|l|c|c|c|c|}
\hline \multirow{2}{*}{ Сорт } & \multicolumn{4}{|c|}{ Дата учета } \\
\cline { 2 - 5 } & 30.06 & 20.07 & 20.08 & 31.08 \\
\hline 1 & 2 & 3 & 4 & 5 \\
\hline \multicolumn{1}{|c|}{ Схема посадки 0,9x0,2 м } \\
\hline Первоклассница (контроль) & 43,0 & 80,3 & 129,3 & 138,0 \\
\hline Анастасия & 39,0 & 88,7 & 144,3 & 152,3 \\
\hline Даренка & 24,7 & 62,3 & 109,0 & 120,7 \\
\hline
\end{tabular}




\begin{tabular}{|c|c|c|c|c|}
\hline \multicolumn{5}{|c|}{ Окончание табл. 3} \\
\hline 1 & 2 & 3 & 4 & 5 \\
\hline Слоненок & 24,0 & 56,3 & 99,0 & 111,3 \\
\hline \multicolumn{5}{|c|}{ Схема посадки 0,9х0,9 м } \\
\hline Первоклассница (контроль) & 38,3 & 83,3 & 140,7 & 148,3 \\
\hline Анастасия & 30,7 & 73,0 & 139,7 & 159,0 \\
\hline Даренка & 23,3 & 54,3 & 108,3 & 120,7 \\
\hline Слоненок & 19,3 & 51,3 & 98,7 & 110,7 \\
\hline
\end{tabular}

Интенсивность роста усов земляники в длину в период ее вегетации неодинакова. В начале лета, до третьей декады июля, среднесуточный прирост их наиболее высокий и составлял 1,88 1,96 см, с 20 июля по 20 августа 1,62-1,87, а с 20 по 31августа лишь 1,01-1,29 см.

Получение стандартной высококачественной рассады земляники садовой является одним из важных этапов в технологии ее выращивания. Посадка качественного посадочного материала в совокупности с комплексом мер по возделыванию гарантирует получение максимальной урожайности данной культуры. Каждое маточное растение земляники может ссормировать растений (розеток) от 12 до 100 шт. и более. Наиболее раннюю и высокого качества рассаду получают из первых узлов, расположенных ближе к материнскому кусту. В зависимости от предполагаемых сроков реализации и посадки рассаду выкапывают в конце лета - начале осени или весной следующего года [12].

Определение выхода рассады земляники осенью, в третьей декаде сентября, показало, что при разреженной схеме (блочной) посадки в маточнике общее число розеток, полученных от одного куста, в 1,3-2,1 раза больше, чем при загущенной. При схеме посадки 0,9×0,2 м общий выход розеток от одного куста варьировал по сортам от 44,2 до 66,1шт., а при схеме 0,9х0,9 м
- от 62,0 до 98,2 шт. (табл. 4). Число стандартных розеток при схеме посадки 0,9×0,2 было в пределах 55,8-77,4\%, что составляло от 31,1 шт. от одного куста у Анастасии до 40,3 шт. у Первоклассницы, при схеме 0,9×0,9 - в пределах $43,2-59,3 \%$, т.е. варьировало от 36,8 шт. у Анастасии и Даренки до 46,4 розеток у Первоклассницы.

Но учитывая то, что число маточных растений на 1 га при блочной посадке было в 4,5 раза меньше, то выход рассады оказался больше при загущенной посадке. Так, выход стандартной рассады с 1 га при схеме посадки 0,9×0,2 м варьировал от 1727,8 тыс. (Анастасия) до 2238,9 тыс. шт. (Первоклассница), то при схеме 0,9х0,9 м этот показатель достоверно снизился до 454,3 тыс. (Анастасия и Даренка) - 572,8 тыс. шт. (Первоклассница). Применение загущенной схемы посадки позволило увеличить выход стандартной рассады сорта Анастасия в 3,8 раза, Первоклассница и Слоненок - в 3,9, а Даренка - в 4,4 раза по сравнению с блочной.

Весной, в середине мая, провели повторную выкопку и учет рассады земляники. Выход стандартной рассады осенью и весной был различный: осенью при обеих схемах посадки по сортам он составлял 43,2-77,4 \%, а весной увеличивался до 72,4-85,7 \% (табл. 4, 5).

Таблица 4

\section{Влияние схемы посадки на выход рассады земляники при выкопке ее осенью (2016-2018 гг.)}

\begin{tabular}{|c|c|c|c|c|c|c|}
\hline \multirow{2}{*}{ Сорт (А) } & \multirow{2}{*}{$\begin{array}{c}\text { Высажено, } \\
\text { тыс. шт/га }\end{array}$} & \multicolumn{2}{|c|}{ Общее число розеток } & \multicolumn{3}{|c|}{ Число стандартных розеток } \\
\cline { 3 - 7 } & 2 & 3 & 4 & 5 & 6 & 7 \\
\hline 1 & 2 & шыс. & $\%$ & шт/куст & тыс. шт/га \\
\hline \multicolumn{7}{|c|}{ Схема посадки 0,9х0,2 м (B) } \\
\hline $\begin{array}{l}\text { Первоклассница } \\
\text { (конкроль) }\end{array}$ & 55,5 & 66,1 & 3672,2 & 60,9 & 40,3 & 2238,9 \\
\hline Анастасия & 55,5 & 55,7 & 3092,6 & 55,8 & 31,1 & 1727,8 \\
\hline
\end{tabular}


Вестник КрасТАУ., 2020. № 4

Окончание табл. 4

\begin{tabular}{|l|c|c|c|c|c|c|}
\hline \multicolumn{1}{|c|}{1} & 2 & 3 & 4 & 5 & 6 & 7 \\
\hline Даренка & 55,5 & 46,8 & 2598,1 & 77,3 & 36,2 & 2011,1 \\
\hline Слоненок & 55,5 & 44,2 & 2457,4 & 77,4 & 34,2 & 1899,9 \\
\hline \multicolumn{5}{|c|}{ Схема посадки 0,9х0,9 м } \\
\hline $\begin{array}{l}\text { Первоклассница } \\
\text { (контроль) }\end{array}$ & 12,3 & 98,2 & 1212,3 & 47,2 & 46,4 & 572,8 \\
\hline Анастасия & 12,3 & 81,6 & 1007,0 & 45,1 & 36,8 & 454,3 \\
\hline Даренка & 12,3 & 62,0 & 765,4 & 59,3 & 36,8 & 454,3 \\
\hline Слоненок & 12,3 & 91,1 & 1125,1 & 43,2 & 39,4 & 486,4 \\
\hline НСР 0 А & & & & & & 116,4 \\
\hline В & & & & & & 432,1 \\
\hline АВ & & & & & 543,3 \\
\hline
\end{tabular}

Таблица 5

Влияние схемы посадки на выход рассады земляники после перезимовки (2017-2019 гг.)

\begin{tabular}{|c|c|c|c|c|c|c|}
\hline \multirow{2}{*}{ Сорт (A) } & \multirow{2}{*}{$\begin{array}{l}\text { Высажено, } \\
\text { тыс. шт/га }\end{array}$} & \multicolumn{2}{|c|}{ Общее число розеток } & \multicolumn{3}{|c|}{ Число стандартных розеток } \\
\hline & & шт/куст & тыс. шт/га & $\%$ & шт/куст & тыс. шт/га \\
\hline \multicolumn{7}{|c|}{ Схема посадки 0,9×0,2 м (B) } \\
\hline Первоклассница (контроль) & 55,5 & 78,2 & 4344,4 & 72,4 & 56,6 & 3144,4 \\
\hline Анастасия & 55,5 & 65,0 & 3611,1 & 85,7 & 55,7 & 3094,4 \\
\hline Даренка & 55,5 & 39,6 & 2198,1 & 81,8 & 32,4 & 1799,9 \\
\hline Слоненок & 55,5 & 40,8 & 2266,6 & 83,8 & 34,2 & 1899,9 \\
\hline \multicolumn{7}{|c|}{ Схема посадки 0,9х0,9 м } \\
\hline Первоклассница (контроль) & 12,3 & 105,1 & 1297,9 & 73,8 & 77,6 & 957,9 \\
\hline Анастасия & 12,3 & 57,4 & 709,0 & 82,2 & 47,2 & 582,7 \\
\hline Даренка & 12,3 & 38,7 & 477,3 & 85,3 & 33,0 & 407,4 \\
\hline Слоненок & 12,3 & 39,2 & 483,9 & 80,3 & 31,5 & 388,9 \\
\hline $\mathrm{HCP}_{05} \mathrm{~A}$ & & & & & & 157,2 \\
\hline$B$ & & & & & & 504,1 \\
\hline$A B$ & & & & & & 632,7 \\
\hline
\end{tabular}

После перезимовки при загущенной посадке выход розеток с одного куста варьировал от 39,6 шт. у Даренки до 78,2 шт. у Первоклассницы, а при разреженной (блочной) - от 38,7 до 105,1 шт. соответственно по сортам. Выход стандартной рассады земляники при выкопке ее весной, за счет позднеосеннего и ранневесеннего роста надземной части и корней, в среднем по всем сортам при загущенной посадке был на 28,8 \%, а блочной - на $21,3 \%$ больше, чем осенью.

\section{Выводы}

1. В условиях Западной Сибири разреженная (блочная) посадка земляники в маточнике способствует лучшему формированию листового аппарата у высаженной рассады. К концу августа число листьев на растении при загущенной схеме посадки 0,9х0,2 м составляет от 8,7 до 14,0 шт., а при разреженной 0,9×0,9 м увеличивается до 12,0-25,7 штук.

2. Появление первых усов земляники в южной лесостепи Омской области наблюдается 10-30 июня, массовое образование - в середине июля второй декаде августа. Сорта земляники при блочной посадке рассады в маточнике отличаются повышенной усообразующей способностью, к концу августа имеют 12,7-19,0 усов на растении, тогда как при загущенной лишь 9,7-13,0 шт. Наиболее длинные усы (138-159 см) имеют сорта Анастасия и Первоклассница, меньше - Даренка и Слоненок - 110,7-120,7 cм. 
3. При разреженной схеме посадки земляники в маточнике к осени от одного куста образуется стандартных розеток больше, но выход рассады с 1 га, из-за разного числа высаженных маточных растений на этой площади, выше в 3,8-4,4 раза при загущенной и составляет по сортам 1727,8-22389 штук. При выкопке земляники весной выход стандартной рассады в среднем по всем сортам при загущенной посадке на $28,8 \%$, а блочной - на 21,3 \% больше, чем при выкопке осенью. При обеих схемах посадки и выкопке осенью выход стандартной рассады сортов земляники составляет 43,2-77,4 \%, а весной - увеличивается до 72,4-85,7 \%. Наибольший выход стандартной рассады с 1 га обеспечивает сорт Первоклассница.

\section{Литература}

1. Савинич Е.A., Мистратова Н.А. Оценка агробиологических признаков сортов земляники в условиях Красноярской лесостепи // Вестник КрасГАУ. 2018. № 4. С. 11-16.

2. Яковенко В.В., Лапшин В.И. Оценка сортов земляники по урожайности и качеству ягод // Плодоводство и виноградарство Юга России. 2014. № 28(04). URL: http://journal.kubansad.ru/pdf/14/04/05.pdf.

3. Кумпан В.Н., Сухоцкая С.Г. Анализ состояния и перспективы развития отрасли садоводства в Омской области // Состояние и перспективы развития садоводства в Сибири: мат-лы II Нац. науч.-практ. конф., посвящ. 85-летию плодового сада Омского ГАУ им. проф. А.Д. Кизюрина. Омск, 2016. C. 7-14.

4. Zhao Y. Berry fruit: Value added products for health promotion. CRC Press Taylor and Francis Group, LLC, Boca Raton, FL. 2007. $430 \mathrm{p}$.

5. Карташов А.П., Сологалов П.В., Хохлова H.A. Сорта и агротехника возделывания земляники в Омской области: метод. рекомендации. Омск, 1988. 32 с.

6. Барсуков Н.И., Рыжков А.П. Ягодные культуры в Омской области. Омск: Омск. кн. изд.-во. 1982. 104 с.

7. Хапова С.А. Научное обоснование технологии культивирования земляники в Северо-
Западном регионе РФ: дис. ... д-ра с.-х. наук: 06.01.08. М., 2016. 406 с.

8. Рыжков А.П. Сибирское плодоводство: учеб. пособие / ОмСХИ. Омск, 1993. Ч. 2. $200 \mathrm{c}$.

9. Советы садоводам Сибири. Барнаул: Алт. кн. изд.-во, 1976. 224 с.

10. Программа и методика сортоизучения плодовых, ягодных и орехоплодных культур / под ред. Е.Н. Седова, Т.П. Огольцовой. Орел: Изд-во ВНИИСПК, 1999. 608 с.

11. ГОСТ Р 53135-2008. Посадочный материал плодовых, ягодных, сбтропических, орехоплодных, цитрусовых культур и чая. Технические условия. М.: Стандартинформ, 2009. $42 \mathrm{c}$.

12. Никиточкина Т.Д., Никиточкина Д.Н. Земляника, клубника. М.: Ниола-Пресс, 2007. $160 \mathrm{c}$.

\section{Literatura}

1. Savinich E.A., Mistratova N.A. Ocenka agrobiologicheskih priznakov sortov zemljaniki v uslovijah Krasnojarskoj lesostepi // Vestnik KrasGAU. 2018. № 4. S. 11-16.

2. Jakovenko V.V., Lapshin V.I. Ocenka sortov zemljaniki po urozhajnosti i kachestvu jagod // Plodovodstvo i vinogradarstvo Juga Rossii. 2014 № 28(04). URL: http://journal.kubansad.ru/pdf/14/04/05.pdf.

3. Kumpan V.N., Suhockaja S.G. Analiz sostojanija i perspektivy razvitija otrasli sadovodstva v Omskoj oblasti // Sostojanie i perspektivy razvitija sadovodstva v Sibiri: matly II Nac. nauch.-prakt. konf., posvjashh. 85letiju plodovogo sada Omskogo GAU im. prof. A.D. Kizjurina. Omsk, 2016. S. 7-14.

4. Zhao Y. Berry fruit: Value added products for health promotion. CRC Press Taylor and Francis Group, LLC, Boca Raton, FL. 2007. $430 p$.

5. Kartashov A.P., Sologalov P.V., Hohlova N.A. Sorta i agrotehnika vozdelyvanija zemljaniki v Omskoj oblasti: metod. rekomendacii. Omsk, 1988. $32 \mathrm{~s}$.

6. Barsukov N.I., Ryzhkov A.P. Jagodnye kul'tury v Omskoj oblasti. Omsk: Omsk. kn. izd.-vo. 1982. $104 \mathrm{~s}$. 
7. Hapova S.A. Nauchnoe obosnovanie tehnologii kul'tivirovanija zemljaniki v SeveroZapadnom regione RF: dis. ... d-ra s.-h. nauk: 06.01.08. M., 2016. $406 \mathrm{~s}$.

8. Ryzhkov A.P. Sibirskoe plodovodstvo: ucheb. posobie / OmSHI. Omsk, 1993. Ch. 2. 200 s.

9. Sovety sadovodam Sibiri. Barnaul: Alt. kn. izd.-vo, 1976. $224 \mathrm{~s}$.

10. Programma i metodika sortoizuchenija plodovyh, jagodnyh i orehoplodnyh kul'tur / pod red. E.N. Sedova, T.P. Ogol'covoj. Orel: Izd-vo VNIISPK, $1999.608 \mathrm{s.}$

11. GOST R 53135-2008. Posadochnyj material plodovyh, jagodnyh, sbtropicheskih, orehoplodnyh, citrusovyh kul'tur i chaja. Tehnicheskie uslovija. M.: Standartinform, 2009. $42 \mathrm{~s}$.

12. Nikitochkina T.D., Nikitochkina D.N. Zemljanika, klubnika. M.: Niola-Press, 2007. $160 \mathrm{~s}$. 